\title{
Spatial-Temporal Distribution Characteristics and Driving Mechanism of Green Total Factor Productivity in China's Logistics Industry
}

\author{
Minjie Li, Jian Wang* \\ School of Economics and Management, Fuzhou University, Fuzhou, China
}

Received: 27 February 2020

Accepted: 26 April 2020

\begin{abstract}
The rapid development of China's logistics industry is accompanied by the deterioration of the ecological environment and excessive energy consumption. Therefore, how to effectively measure and improve the green total factor productivity (GTFP) of the logistics industry is an important guarantee for achieving the coordination of the logistics industry development and the ecological environment protection in the high-quality development stage. This study evaluated the logistics industry's GTFP of 30 provinces in China from 2004 to 2017 using the Epsilon-based measure model (EBM) and global Malmquist-Luenberger index (GML). Then, this paper applied the geographically and temporally weighted regression (GTWR) to analyze the spatiotemporal non-stationarity of influences of driving factors on GTFP. There are three main conclusions drawn in this paper. Firstly, the GTFP of the logistics industry has significant spatial and temporal differences. From a temporal perspective, the GTFP has undergone a process of alternating changes in ascent and descent. From a spatial perspective, the GTFP has an obvious "east-central-west" gradient decreasing trend. Secondly, compared with the ordinary least squares (OLS) and the geographically weighted regression (GWR), GTWR performs best in terms of goodness of fit. Thirdly, the regression results of GTWR indicate that the influences of factors have different directions and intensities on GTFP in the logistics industry at different times and regions, showing obvious characteristics of spatiotemporal non-stationarity. Finally, some practical recommendations are put forward in this paper.
\end{abstract}

Keywords: logistics industry, Epsilon-based measure model, global Malmquist-Luenberger index, spatiotemporal non-stationarity, geographically and temporally weighted regression

*e-mail: wcctxwb@hotmail.com 


\section{Introduction}

In recent years, the logistics industry, which integrates transportation, warehousing, freight forwarding and information industry, is regarded as the basic and strategic industry to support the social and economic development and is called "the third profit source" [1]. Although the logistics industry belongs to the service industry, it has become one of the major industries in energy consumption. In China, the quantity of more than $90 \%$ of gasoline and more than $60 \%$ of diesel are consumed by the logistics industry. Thus, the traditional extensive growth mode with such high investment, high pollution and low efficiency makes the logistics industry face severe resource and environmental constraints. At present, the scale of logistics is expanding rapidly, while the demand for logistics has increased dramatically in China. Therefore, how to continue to improve the quality of the logistics industry while reducing energy consumption and carbon dioxide emissions is an urgent issue to be considered. On the whole, in order to realize the sustainable development of the logistics industry, it is necessary to change from extensive growth driven by resource input to intensive growth driven by total factor productivity (TFP).

According to whether the production function needs to be set, there are two main methods to calculate TFP: parametric method and nonparametric method. Because parametric methods require strict assumptions, the data envelopment analysis (DEA) first proposed by Charnes et al. in 1978, was quickly recognized by the international academia and applied in a diverse array of fields [2]. For instance, Markovits and Bokor [3] adopted a novel DEA-PC (pairwise comparison) method to evaluate the logistics efficiency of 29 European countries. Zhang et al. [4] used the DEA-Malmquist index to measure the TFP of agricultural product logistics, and decomposed TFP into pure technical efficiency and scale efficiency. Wang et al. [5] applied a model combining DEA and Shephard distance function, namely production-theoretical decomposition analysis (PDA), to explore the influencing factors of industrial carbon emission intensity changes. In recent years, with the increasingly important role of environmental issues in sustainable development, when applying the TFP to evaluate the efficiency of economic growth, we must consider not only traditional inputs such as capital and labor, but also the effects of resource consumption and environmental pollution on economic growth [6,7]. Otherwise, it may overestimate the true performance of economic growth [8]. Therefore, Chambers et al. [9] and Chung et al. [19] constructed the Directional Distance Function (DDF), added carbon emissions as the undesired outputs of the production process to the TFP framework, and reasonably evaluating the restrictive role of environmental factors. TFP that considers undesired outputs is called green total factor productivity (GTFP). That means, it can better reflect the essence of energy-saving and emission-reduction [11].

Meanwhile, existing studies have explored the driving factors of GTFP. For instance, Shen et al. [12] constructed a panel model to analyze different types of environmental regulations on GTFP in China. Furthermore, the green spillover effect of foreign direct investment (FDI) on GTFP is a concern for host countries. Simpson [13] and Herrigel [14] focused on the impacts of FDI on GTFP in developed countries while Hu et al. [15] and Zhou et al. [16] focused on that of in developing countries. Additionally, Cui et al. [17] used a systematic generalized moment method to evaluate the growth trend of GTFP in 36 industrial sectors in China and explore the factors that influencing GTFP. Rahman and Salim [18] analyzed 6 main influencing factors of agricultural GTFP in Bangladesh. Moreover, fiscal decentralization, international policies and fiscal development are also major factors affecting GTFP [19-21]. However, there is still a lack of research on the driving factors of GTFP in the logistics industry. Liu et al. [1] examined the influence of tax reform on energy efficiency in the logistics industry. Besides, Yang et al. [22] adopted DEA-Malmquist to analyze the carbon emission efficiency of logistics in 16 cities in Yunnan, and used Tobit to capture the driving factors of the carbon emissions performance in logistics. Moreover, Yang et al. [23] adopted the slacks-based measure (SBM) model and the global Malmquist-Luenberger index (GML) to analyze the total factor energy efficiency of the logistics industry along the Yangtze River Economic Zone from 2004 to 2013.

Although there have been studies on issues related to the logistics industry, there still exist some deficiencies in the existing researches. First, the calculation of TFP in the logistics industry is defective. Although some researches have considered carbon emissions as an undesirable output when measuring the TFP, the methods are either radial or non-radial, and the technical reference set is not global. This makes the above models have some defects. Therefore, this paper used the panel data of the logistics industry in 30 provinces in China from 2004 to 2017, added carbon emissions into the measurement system as an undesirable output, then adopted the Epsilon-based measure model (EBM) and the global Malmquist-Luenberger index (GML) to measure GTFP. Second, the mechanism for changes in GTFP of the logistics industry is complicated. Thus, the magnitude and direction of the influences of factors on GTFP in the logistics industry may be different over time. In identifying the influence direction and intensity of the driving factors in different provinces, the constant coefficient spatial measurement model cannot meet the research requirements. The geographically and temporally weighted regression (GTWR) was used to analyze the influences of the driving factors on GTFP of the logistics industry.

The rest of this paper is organized as follows. Section 2 introduces three adopted models in this 
paper, namely the EBM, the GML and the GTWR, respectively. Section 3 presents the spatial and temporal distribution characteristics of GTFP in the logistics industry in China. Section 4 uses the GTWR model to empirically analyze the driving mechanism of GTFP in the logistics industry. Section 5 summarizes the study and makes recommendations.

\section{Methods}

\section{Epsilon-Based Measure (EBM)}

The traditional radial distance function requires the inputs and outputs to be adjusted in the same proportion, which is contrary to the real economy. Similarly, although the SBM model circumvents the assumption that the inputs and outputs are reduced in the same proportion, it loses the proportional information between the target value and the actual value of the inputs and outputs [24]. Accordingly, Tone and Tsutsui [25] constructed a nonoriented EBM model combining radial and non-radial characteristics. Meanwhile, considering the undesirable output, this study further constructs an EBM model which includes the undesirable output [26] as follows:

$$
\begin{gathered}
\tau^{*}=\min \frac{\theta-\varepsilon_{x} \sum_{i=1}^{m} \frac{w_{i}^{-} s_{i}^{-}}{x_{i k}}}{\varphi+\varepsilon_{y} \sum_{r=1}^{s} \frac{w_{r}^{+} s_{r}^{+}}{y_{r k}}+\varepsilon_{b} \sum_{p=1}^{q} \frac{w_{p}^{b_{-}} s_{p}^{b_{-}}}{b_{p k}}} \\
\text { s.t. } \sum_{j=1}^{n} \lambda_{j} x_{i j}+s_{i}^{-}=\theta x_{i k}(i=1,2, \cdots, m) \\
\sum_{j=1}^{n} \lambda_{j} y_{r j}-s_{r}^{+}=\varphi y_{r k}(r=1,2, \cdots, s) \\
\sum_{j=1}^{n} \lambda_{j} b_{i j}+s_{p}^{b^{-}}=\varphi b_{p k}(p=1,2, \cdots, q) \\
w_{i}^{-}=\frac{w_{i}}{\sum_{i=1}^{m} w_{i}} \\
\lambda_{j} \geq 0, s_{i}^{-} \geq 0, s_{r}^{+} \geq 0, s_{p}^{b^{-}} \geq 0, \theta \leq 1, \varphi \leq 1
\end{gathered}
$$

...where $\tau^{*}$ denotes the efficiency value considering the undesirable output under the variable returns to scale (VRS) [27]; $\lambda$ represents the linear combination coefficient of decision units; $\theta$ is the efficiency value calculated by radial model, while $\varepsilon$ denotes the importance of the non-radial part when calculating the efficiency value. In addition, $x_{i k}, y_{r k}$ and $b_{p k}$ represent the specific input $i$, the specific desirable output $r$ and the specific undesirable output $p$ of the specific decision making unit $k$, respectively. Moreover, $s_{i}^{-}, s_{r}{ }^{+}$and $s_{p}{ }^{b+}$ denote the slacks of the specific input $i$, the specific desirable output $r$ and the specific undesirable output $p$, respectively. Additionally, $w_{i}^{-}, w_{r}^{+}$and $w_{p}{ }^{b+}$ represent the relative weights of the specific input $i$, the specific desirable output $r$ and the specific undesirable output $p$, respectively, and satisfy $\sum_{i=1}^{m} w_{i}^{-}=1\left(w_{i}^{-} \geq 0\right) . x_{i j}, y_{r j}$, and $b_{i j}$, denote the quantity of inputs, desirable outputs and undesirable outputs.

\section{Global Malmquist-Luenberger (GML)}

Oh [28] proposed the GML index based on global production technology. The combination of the EBM model with the GML index is adopted to calculate the GTFP of the logistics industry. Therefore, the expression formulae of the GML index are as follows:

$$
\vec{D}_{0}\left(x^{t}, y^{t}, b^{t} ; g\right)=\sup \left\{\beta:\left(y^{t}+\beta g_{y}, b^{t}+\beta g_{b}\right) \in P^{t}\left(x^{t}+\beta g_{x}\right)\right\}
$$

...where $g=(-x, y,-b)$, and it represents that under the given technical conditions, the desirable output $y$ increases proportionally while the undesirable output $b$ and input $x$ shrink proportionally. Besides, $\beta$ represents the maximum possible value of increase and decrease.

$$
G M L_{t}^{t+1}=\frac{1+\vec{D}_{0}^{G}\left(x^{t}, y^{t}, b^{t} ;-x^{t}, y^{t},-b^{t}\right)}{1+\vec{D}_{0}^{G}\left(x^{t+1}, y^{t+1}, b^{t+1} ;-x^{t+1}, y^{t+1},-b^{t+1}\right)}
$$

...where $G M L_{t}^{t+1}$ denotes the ratio of the region's TFP for the year to the previous year. A $G M L_{t}^{t+1}$ greater (or less) than 1 indicates a growth (or decrease) in TFP during the period from $t$ to $t+1$. It should be noted that $G M L_{t}^{t+1}$ can be decomposed into the global technology progress change index GTECH $_{t}^{t+1}$ and the global technology efficiency change index $\mathrm{GEFFCH}_{t}^{t+1}$. The formula for formal decomposition is as follows:

$$
\begin{gathered}
G M L_{t}^{t+1}=G T E C H_{t}^{t+1} \times G E F F C H_{t}^{t+1} \\
G T E C H_{t}^{t+1}=\frac{1+\vec{D}_{0}^{G}\left(x^{t}, y^{t}, b^{t} ;-x^{t}, y^{t},-b^{t}\right)}{1+\vec{D}_{0}^{t}\left(x^{t}, y^{t}, b^{t} ;-x^{t}, y^{t},-b^{t}\right)} \times \frac{1+\vec{D}_{0}^{t+1}\left(x^{t+1}, y^{t+1}, b^{t+1} ;-x^{t+1}, y^{t+1},-b^{t+1}\right)}{1+\vec{D}_{0}^{G}\left(x^{t+1}, y^{t+1}, b^{t+1} ;-x^{t+1}, y^{t+1},-b^{t+1}\right)}
\end{gathered}
$$

$$
\operatorname{GEFFCH}_{t}^{t+1}=\frac{1+D_{0}^{t} x^{t}, y^{t}, b^{t} ;-x^{t}, y^{t},-b^{t}}{1+D_{0}^{t+1}\left(x^{t+1}, y^{t+1}, b^{t+1} ;-x^{t+1}, y^{t+1},-b^{t+1}\right)}
$$

...where GTECH $_{t}^{t+1}$ greater (or less) than 1 reflects technological progress (or regression), while that of $\mathrm{GEFFCH}_{t}^{t+1}$ reflects technical efficiency improvement (or decline). 
Geographically and Temporally Weighted Regression (GTWR)

Traditional statistical models cannot reflect the spatial heterogeneity between regions. Thus, the geographically weighted regression (GWR), as a local variable coefficient model that can identify spatial nonstationarity, was proposed in the 1990s and widely used in different fields [29]. However, the GWR model cannot observe changes at different points in time. Therefore, Huang et al. [30] and Fotheringham et al. [31] proposed a spatiotemporal variable coefficient model, namely GTWR, and proved that this method is superior to GRW and traditional spatial econometric models. Specifically, GTWR estimates each parameter at different points in time. Compared with GWR, it has higher estimation efficiency and model superiority [32, 33]. The general equation of the GTWR model is as follows:

$$
y_{i}=\beta_{0}\left(u_{i}, v_{i}, t_{i}\right)+\sum_{k=1}^{6} \beta_{k}\left(u_{i}, v_{i}, t_{i}\right) x_{i k}+\varepsilon_{i}
$$

...where $y_{i}$ denotes the dependent variable in the specific region $i$. Additionally, $x_{i k}$ denotes the observations of the dependent variable $k$ in the specific region $i .\left(u_{i}, v_{i}\right.$, $\left.t_{i}\right)$ refers to the space-time coordinate location of the specific region $i$. Furthermore, $\beta_{0}\left(u_{i}, v_{i}, t_{i}\right)$ and $\beta_{k}\left(u_{i}\right.$, $v_{i}, t_{i}$ ) denote the intercept term and the regression coefficients of the dependent variable $k$ in the specific region $i . \varepsilon_{i}$ represents the residual. In the GTWR model, the regression coefficient of the independent variable $k$ at the specific region $i$ is estimated by the least square method. The spatial weight function commonly used in the GTWR model is Gaussian function.

$$
\begin{gathered}
W_{i j}=\exp \left\{-\left(d_{i j} / h\right)^{2}\right\} \\
h=\min C V=\sum\left[y_{i}-\hat{y}_{i \neq i}(h)\right]^{2} \\
d_{i j}=\sqrt{\lambda\left[\left(u_{i}-u_{j}\right)^{2}+\left(v_{i}-v_{j}\right)^{2}\right]+\mu\left(t_{i}-t_{j}\right)^{2}}
\end{gathered}
$$

...where $d_{i j}$ denotes the space-time distance between the $i$ sample point and the $j$ sample point. $\hat{y}_{i}$ stands for fitting value. $h$ denotes broadband. $C V$ is Cross-Validation.

\section{Materials}

\section{Data Sources}

Currently, the Chinese National Economy Industry Classification and Codes compiled and released by the National Bureau of Standards of China does not specify the logistics industry, but only the transportation, warehousing, and postal industries. According to the data of China Logistics Yearbook, the outputs of transportation, warehousing, and postal industry accounts for more than $85 \%$ of the total outputs of the logistics industry. Therefore, the above indicator can basically reflect the development of the logistics industry. This paper selects 30 provinces but except Hong Kong, Macao, Taiwan, and Tibet in China as the study area, and the research time is from 2004 to 2017. In addition, the data comes from China Statistical Yearbook, China Energy Statistical Yearbook, China Tertiary Industry Statistical Yearbook. Furthermore, in the case of missing data, it is supplemented by the statistical yearbooks of each province.

\section{Variables Selection}

\section{Input Variables}

The actual capital stock (ACS) of the logistics industry in each province from 2004 to 2017 calculated based on the perpetual inventory approach was used as the proxy indicator of the capital stock. The capital stock can be calculated as follows:

$$
K_{i, t}=K_{i, t-1}(1-\delta)+I_{i, t} / P_{t}
$$

...where $I_{i, t}$ denotes the investment in the fixed assets of logistics industry in the specific area $i$ in the specific year $t$. Additionally, $P$ represents the deflator for fixed asset investment while $\delta$ is the depreciation rate. Regarding the selection of the depreciation rate, Liu et al. [1] selected $10.96 \%$, and Tang et al. [34] calculated it once a year. Considering the characteristics of the logistics industry, this paper directly adopts Wu's research results, that is, the depreciation rate is $4 \%$ [35]. Thus, the base period capital stock $K_{i, t}$ is equal to $\int^{1} I_{i, t} d t$ [36]. Besides, the labor force (LF) is measured by the number of employees in the logistics industry. Furthermore, the energy consumption (EC) is obtained by converting the 8 types of energy which are consumed most by logistics industry into standard coal. The above 8 types are raw coal, coke, crude oil, gasoline, kerosene, diesel, fuel oil and natural gas.

\section{Output Variables}

The added value (ADV) of the logistics industry is applied to measure the desirable output. In addition, taking 2004 as the base period, the added value of the tertiary industry is adopted to deflate the added value of the logistics industry. Furthermore, carbon emissions (CS) are adopted as an undesirable output. Specifically, based on the energy consumption, carbon emissions of the logistics industry by province are measured. Overall, this paper uses the following formula released in the 2006 IPCC Guidelines for National Greenhouse Gas Inventories (2006 IPCC Guidelines) to measure carbon emissions: 


$$
C=\sum_{i=1}^{8} C_{i}=\sum_{i=1}^{8} E_{i} \times N C V_{i} \times C E F_{i} \times C O F_{i}
$$

...where $E_{i}$ denotes the energy consumption of the specific energy $i$. $N C V_{i}$ enotes the average low calorific value cited from China Energy Statistical Yearbook while $C E F_{i}$ eans the carbon emission coefficient provided by IPCC. $C O F_{i}$ represents the carbon oxidation factor, and the default value applied by IPCC is 1 . The emission coefficients adopted in this paper to measure carbon emissions can be listed in Table 1 .

\section{Driving Factors}

Human resources (HR) are more important determinants of economic growth than physical capital $[37,38]$. Because education is a major predictor of the accumulation of human capital [39], this paper uses the number of students being educated as a measure of human resources. The number of students is equal to the proportion of middle-school students and college students in the total regional population.

Besides, although the influence of $R \& D$ investment in GTFP is unclear [40, 41], it is an important indicator of the level of science and technology investment in a region. Therefore, this paper adopts the intensity of $R \& D$ investment (RD) as one of the driving factors. The intensity of $R \& D$ investment is equal to the proportion of research and experimental development expenditure in the regional GDP.

Industrial agglomeration (IA) is also one of the driving factors. Specifically, the spatial agglomeration of economic activities is conducive to sharing transportation infrastructure, reducing carbon emissions, and promoting the growth of GTFP. However, when the scale of the agglomeration continues to expand, the enterprises in the agglomeration area will face constraints on environmental carrying capacity and rising prices of factors of production, which will produce a congestion effect. Moreover, there may also be an inverted "U" relationship between industrial agglomeration and GTFP [42]. The location entropy of the logistics industry is applied to measure the level of logistics industry agglomeration.
In addition, through FDI, excellent talents and advanced technologies can be introduced into the local logistics industry. However, the continuous inflow of FDI may also exacerbate pollutant emissions [43]. Therefore, this paper applies the proportion of FDI in each province to GDP (FDI) to examine the influence of FDI on the logistics industry's GTFP. Moreover, informatization has penetrated into every node of the logistics industry such as transportation, warehousing, loading and unloading, handling, and packaging, making the various nodes of logistics better connected and configured.

Informatization has improved the service quality and production efficiency of the logistics industry by reducing costs and increasing revenues $[44,45]$. Thus, the total volume of postal and telecommunication services is applied to measure the informatization level (INF).

Transportation is the main source of carbon emissions from the logistics industry. That is to say, the government's adjustment and optimization of the transportation structure can simultaneously reduce carbon emissions, transportation costs and improve logistics efficiency. Meanwhile, highway transportation accounts for a majority of carbon emissions from the transport sector in China [46]. Thus, the proportion of highway cargo turnover to total cargo turnover is used in this paper to measure the transportation structure (TS). Descriptive statistics of all variables can be seen in Table 2.

\section{Results and Discussion}

\section{Measurement of GTFP in the Logistics Industry}

Based on the input-output data of various regions from 2004 to 2017, this paper uses MAX DEA Pro6.4 software to calculate the GML index based on the EBM model. The evolution of the GML index over time is shown in Fig. 1. In terms of time, the average value of GML in China's logistics industry from 2004 to 2017 indicated a process of alternating changes in ascent

Table 1. Coefficient of Carbon Emissions in Logistics Industry.

\begin{tabular}{|c|c|c|c|c|}
\hline Energies & $\begin{array}{c}\text { Average low calorific } \\
\text { value }\end{array}$ & $\begin{array}{c}\text { IPCC (2006) } \\
\text { carbon emission coefficient }\end{array}$ & $\begin{array}{c}\text { Carbon oxidation } \\
\text { factor }\end{array}$ & $\begin{array}{c}\text { Standard coal } \\
\text { conversion coefficient }\end{array}$ \\
\hline Coal & $20908 \mathrm{~kJ} / \mathrm{kg}$ & $25.8 \mathrm{kgC} / \mathrm{GJ}$ & 1 & $0.7143 \mathrm{kgC} / \mathrm{kgce}$ \\
\hline Coke & $28435 \mathrm{~kJ} / \mathrm{kg}$ & $29.2 \mathrm{kgC} / \mathrm{GJ}$ & 1 & $0.9714 \mathrm{kgC} / \mathrm{kgce}$ \\
\hline Crude & $41816 \mathrm{~kJ} / \mathrm{kg}$ & $20.0 \mathrm{kgC} / \mathrm{GJ}$ & 1 & $1.4286 \mathrm{kgC} / \mathrm{kgce}$ \\
\hline Gasoline & $43070 \mathrm{~kJ} / \mathrm{kg}$ & $18.9 \mathrm{kgC} / \mathrm{GJ}$ & 1 & $1.4714 \mathrm{kgC} / \mathrm{kgce}$ \\
\hline Kerosene & $43070 \mathrm{~kJ} / \mathrm{kg}$ & $19.6 \mathrm{kgC} / \mathrm{GJ}$ & 1 & $1.4714 \mathrm{kgC} / \mathrm{kgce}$ \\
\hline Diesel & $42652 \mathrm{~kJ} / \mathrm{kg}$ & $20.2 \mathrm{kgC} / \mathrm{GJ}$ & 1 & $1.4517 \mathrm{kgC} / \mathrm{kgce}$ \\
\hline Fuel oil & $41816 \mathrm{~kJ} / \mathrm{kg}$ & $21.1 \mathrm{kgC} / \mathrm{GJ}$ & 1 & $1.4286 \mathrm{kgC} / \mathrm{kgce}$ \\
\hline Natural gas & $38931 \mathrm{~kJ} / \mathrm{m}^{3}$ & $15.3 \mathrm{kgC} / \mathrm{GJ}$ & 1 & $1.3300 \mathrm{kgC} / \mathrm{kgce}$ \\
\hline
\end{tabular}


Table 2. Descriptive statistics of all selected variables.

\begin{tabular}{|c|c|c|c|c|c|c|c|}
\hline $\begin{array}{c}\text { Variable } \\
\text { category }\end{array}$ & Variables & Unit & Min & Max & Mean & Std. D & Data Sources \\
\hline \multirow{4}{*}{\begin{tabular}{c} 
Input variables \\
\cline { 2 - 8 }
\end{tabular}} & $\mathrm{ACS}$ & 100 million USD & 17.53 & 2376.77 & 550.93 & 441.22 & Provincial Statistical Yearbook \\
\cline { 2 - 8 } & $\mathrm{EC}$ & $10^{4}$ persons & 2.67 & 85.40 & 22.77 & 14.27 & $\begin{array}{c}\text { China Tertiary Industry Statistical } \\
\text { Yearbook }\end{array}$ \\
\hline $\begin{array}{c}\text { Desirable output } \\
\text { output }\end{array}$ & $\mathrm{ADV}$ & 100 million USD & 3.62 & 530.37 & 116.20 & 101.69 & China Statistical Yearbook \\
\hline \multirow{4}{*}{\begin{tabular}{c} 
Driving factors \\
\cline { 2 - 8 }
\end{tabular}} & $\mathrm{CS}$ & $10^{4}$ tons & 6.02 & 1847.16 & 489.12 & 338.68 & China Energy Statistical Yearbook \\
\cline { 2 - 8 } & $\mathrm{HR}$ & $\%$ & 0.5539 & 1.1269 & 0.8154 & 0.1079 & Provincial Statistical Yearbook \\
\cline { 2 - 8 } & $\mathrm{FDI}$ & $\%$ & 0.0017 & 0.0601 & 0.0139 & 0.0105 & Provincial Statistical Yearbook \\
\cline { 2 - 8 } & $\mathrm{INF}$ & 100 million USD & 3.1582 & 904.3494 & 104.03 & 106.1988 & China Energy Statistical Yearbook \\
\cline { 2 - 8 } & $\mathrm{TS}$ & $\%$ & 0.0053 & 0.8140 & 0.3567 & 0.2081 & Provincial Statistical Yearbook \\
\hline
\end{tabular}

and descent. Specifically, it can be roughly divided into four stages. The first stage is from 2004 to 2008. At this stage, GTFP in the logistics industry shows a continuous upward trend, and GEFFCH is less than 1, that is, the improvement of GTECH is the main driving force for the development of GTFP. This is mainly because in the early stage of the development of China's logistics industry, more comprehensive reform measures were introduced, which promoted the spread of new logistics ideas and concepts and drove the progress of logistics technology. However, the GTFP level of the logistics industry was relatively low during this period, indicating that the logistics industry is still in an extensive development state. The second stage is from 2008 to 2009. The minimum values of the GML index and GEFFCH index both appear in this stage, which may be affected by the 2008 international economic and

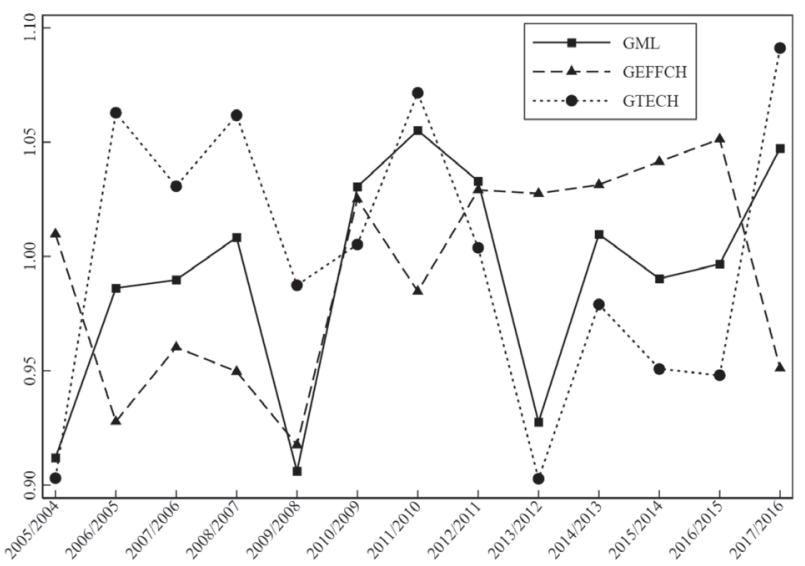

Fig. 1. Time trend of GML and the decomposition indexes from 2004 to 2017. financial crisis. The third stage is from 2010 to 2014. Although GTFP in this stage of the logistics industry has not maintained a continuous upward trend, the GTFP value is greater than 1 except 2013. This is the result of the GTECH index and the GEFFCH index alternating greater than 1 . One possible explanation is that as the global economy picks up, the domestic and foreign markets are getting better, and the logistics growth momentum is strong, so logistics technology progress and technical efficiency have been rapidly developed. The fourth stage is from 2015 to 2016. At this stage, environmental problems caused by the rapid development of the logistics industry are gradually emerging. When each department of the logistics industry is required to increase the expected output as much as possible, it may often lead to an increase in pollution emissions. Therefore, the GTFP of the logistics industry was less than 1 in 2015 and 2016. In contrast, in 2017, the logistics industry GTFP showed a slight rebound, reaching 1.0473, which may be the result of China's environmental control measures. Furthermore, the GTECH index and the GML index have a higher degree of curve fitting, which is consistent with the research conclusion conducted by Liu et al. [1]. That means, the logistics industry still needs to increase investments of new energy, rely on talent advantages and strengthen technological innovation. Meanwhile, we must also continue to focus on the innovation of the management model and increase the contribution of green technology efficiency to GTFP growth.

From the spatial perspective, as shown in Fig. 2, there exist obvious differences between provinces in the average of GML index, GTECH index and GEFFCH index. As can be seen in Fig. 2a), the provinces with a higher average of GML index in the logistics industry are mainly distributed in the east, while that of with a 
lower average of GML index are mainly in the central and western regions, such as Yunnan, Heilongjiang, and Qinghai. Additionally, as can be seen in Fig. 2b), the provinces with a higher average of GTECH index are mainly distributed in the east and central areas, such as Zhejiang, Guangdong, and Jiangxi, while that of with a lower average are mainly distributed in the west. Moreover, as shown in Fig. 2c), the provinces with a higher average of GEFFCH index are mainly distributed in Jiangsu, Liaoning, Shanxi and Henan, while that of with a lower average are mainly distributed in Yunnan, Jilin, and Heilongjiang. One possible explanation is that compared to the central and western regions, the eastern region opened earlier and its economy was much more developed, which improved the logistics infrastructure.
Meanwhile, the eastern area has gathered a large number of powerful scientific research institutions, universities and enterprises, making the region's innovation capacity and technological level significantly higher than the rest regions. The backward economic development, weak infrastructure, underdeveloped transportation, and lack of talents in the central and western regions have led to a small logistics demand and a small logistics market.

\section{Results Calculated by GTWR}

\section{Model Comparison}

In order to further verify the spatiotemporal nonstationarity of the growth mechanism of GTFP in
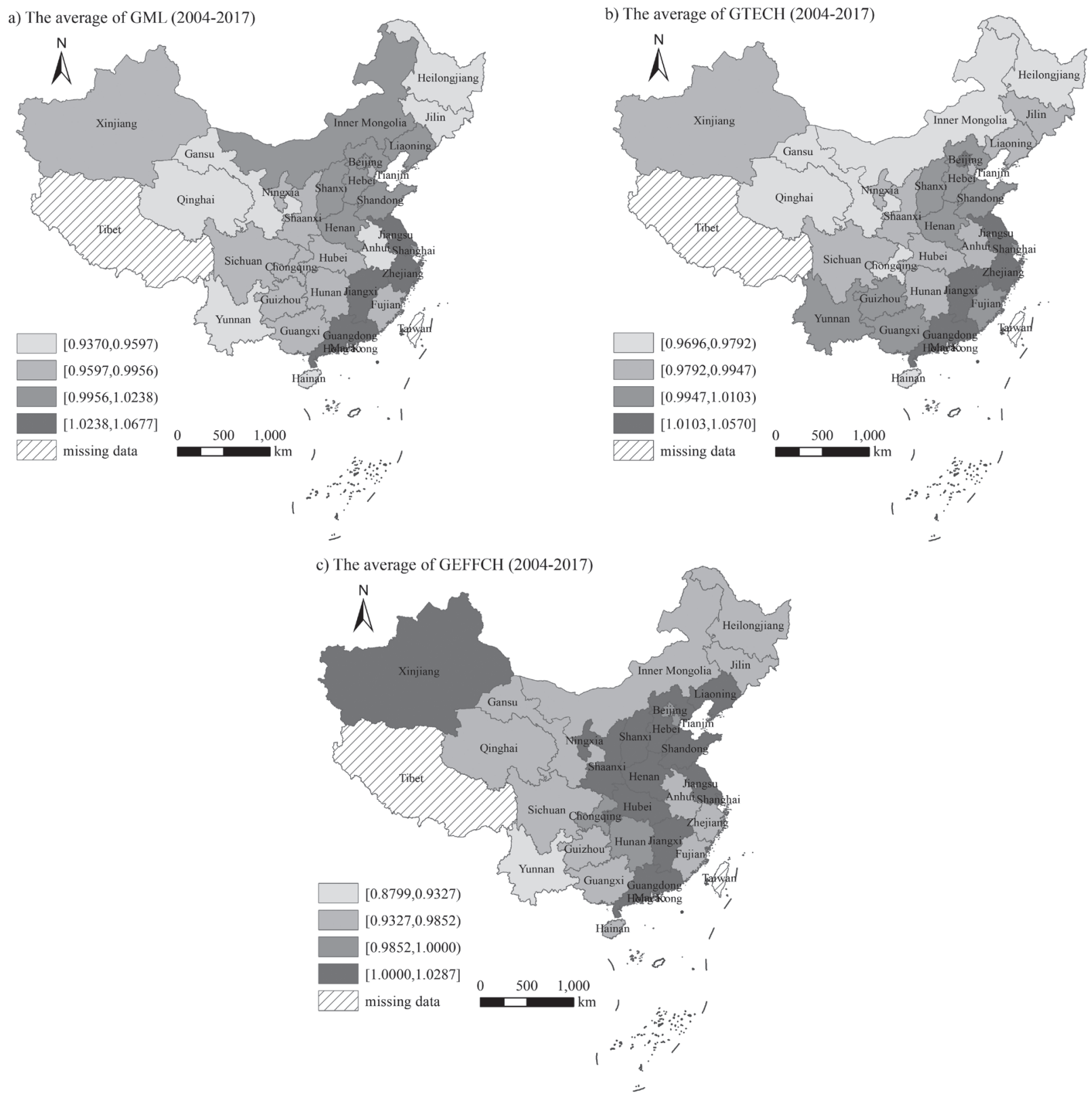

Fig. 2. Spatial distribution of average GML index of logistics industry and its decomposition trend from 2004 to 2017. 
Table 3. The comparison of the coefficient results calculated by OLS, GWR and GTWR.

\begin{tabular}{|c|c|c|c|c|c|c|c|c|}
\hline \multirow{2}{*}{ Variables } & \multicolumn{2}{|c|}{ OLS } & \multicolumn{3}{|c|}{ GWR } & \multicolumn{3}{|c|}{ GTWR } \\
\hline & Coef. & $\mathrm{p}$ & Min & Max & Mean & Min & Max & Mean \\
\hline Intercept & 0.2989 & 0.1935 & -0.9892 & 1.9130 & 0.0048 & -2.5665 & 2.3728 & 0.0137 \\
\hline HR & 0.1318 & 0.2574 & -0.8123 & 1.8545 & 0.1312 & -2.5835 & 2.8080 & 0.2688 \\
\hline $\mathrm{RD}$ & 0.0875 & 0.0053 & -0.2024 & 0.3399 & 0.0322 & -0.3869 & 0.6675 & 0.0282 \\
\hline IA & -0.1376 & 0.0481 & -0.6283 & 0.5379 & -0.0741 & -2.7188 & 1.0405 & -0.0053 \\
\hline FDI & 0.0441 & 0.0103 & -0.0707 & 0.2354 & 0.0656 & -0.1169 & 0.4853 & 0.0935 \\
\hline INF & 0.0373 & 0.0962 & -0.2506 & 0.2210 & 0.0580 & -0.3933 & 0.5240 & 0.0862 \\
\hline TS & -0.0199 & 0.2771 & -0.4177 & 0.6771 & -0.0167 & -0.7092 & 0.9629 & -0.0178 \\
\hline $\mathrm{R}^{2}$ & \multicolumn{2}{|c|}{0.1337} & \multicolumn{3}{|c|}{0.6734} & \multicolumn{3}{|c|}{0.7927} \\
\hline F & \multicolumn{2}{|c|}{10.6234} & \multicolumn{3}{|c|}{141.9239} & \multicolumn{3}{|c|}{263.2136} \\
\hline SSR & \multicolumn{2}{|c|}{36.4351} & \multicolumn{3}{|c|}{13.7687} & \multicolumn{3}{|c|}{8.7417} \\
\hline AIC & \multicolumn{2}{|c|}{179.125} & \multicolumn{3}{|c|}{-127.446} & \multicolumn{3}{|c|}{-193.558} \\
\hline
\end{tabular}

China's logistics industry, this paper first constructs the ordinary least square (OLS), GWR, and GTWR models, then compares the results of the above three regression models. As shown in Table 3, the estimation results of explanatory variables calculated based on OLS are between the minimum and maximum values of the corresponding variables estimated based on GTWR. Additionally, the values of R-square and F value of GTWR are larger than that of GWR and OLS, while the sum of squared residuals (SSR) of GTWR is smaller than that of GWR and OLS. Furthermore, as a measure of the goodness of fit of a model, the smaller the Akaike information criterion (AIC) value, the higher the accuracy of the model [47]. As can be seen in Table 3, GTWR has the smallest AIC value among the above three selected models. Specifically, the difference between the AIC value of GTWR and that of GWR and OLS is over 3 , indicating that the former estimates is superior to the estimates of GWR and OLS [48].

\section{The Time Evolution of the Influences of Factors on GTFP}

In order to accurately analyze the time evolution of the influences of various factors on the logistics industry's GTFP, box charts are adopted in this paper to indicate the time evolution trend of the regression coefficients of each influencing factor, as shown in Fig. 3. Human resources have a great positive influence on GTFP in the logistics industry. That is, driven by the "develop the country through science and education" and "reinvigorating China through human resource development" strategies, recently, the quality and skills of the labor forces in logistics industry continue to be improved, which is conducive to the improvement of green technology efficiency and technological progress. Besides, except in 2015, R\&D investment has positively promoted GTFP in the logistics industry. That is, the increase in $R \& D$ investment provides funding for the research and promotion of green technologies. Moreover, the annual average values of the regression coefficients of industrial agglomeration are between -2.7188 and 1.0405. Specifically, the regression coefficients from 2004 to 2010 are all positive values, indicating that industrial agglomeration played a positive role in the logistics industry's GTFP during this period. Since 2010, the regression coefficients of industrial agglomeration are all negative and keep decreasing, indicating that the scale of the logistics industry agglomeration during this period was too large, and the congestion effect exceeded the scale effect, which was not conducive to the improvement of logistics industry's GTFP.

From 2004 to 2017, the regression coefficients of FDI were all positive. Specifically, from 2004 to 2010, the promotion influences of FDI on GTFP in the logistics industry continued to increase, and the average value of the regression coefficients reached a maximum of 0.1178 in 2010. However, from 2011 to 2017, the promotion influences of FDI on GTFP in the logistics industry gradually weakened. Thus, since the $21^{\text {st }}$ century, China has been actively attracting foreign capital. That means FDI can both directly promote economic growth through capital investment and indirectly increase green productivity through technology spillovers. Besides, the average value of the regression coefficients of INF from 2004 to 2017 has been increasing. It also indicates that since 2008, the influences of the level of informatization on the logistics industry's GTFP has changed from a negative effect to a positive effect. During the research period, the informatization level of the logistics industry rose from 38.9177 to 183.4499 . The increase in the informatization level can reduce the carbon emissions of the logistics 

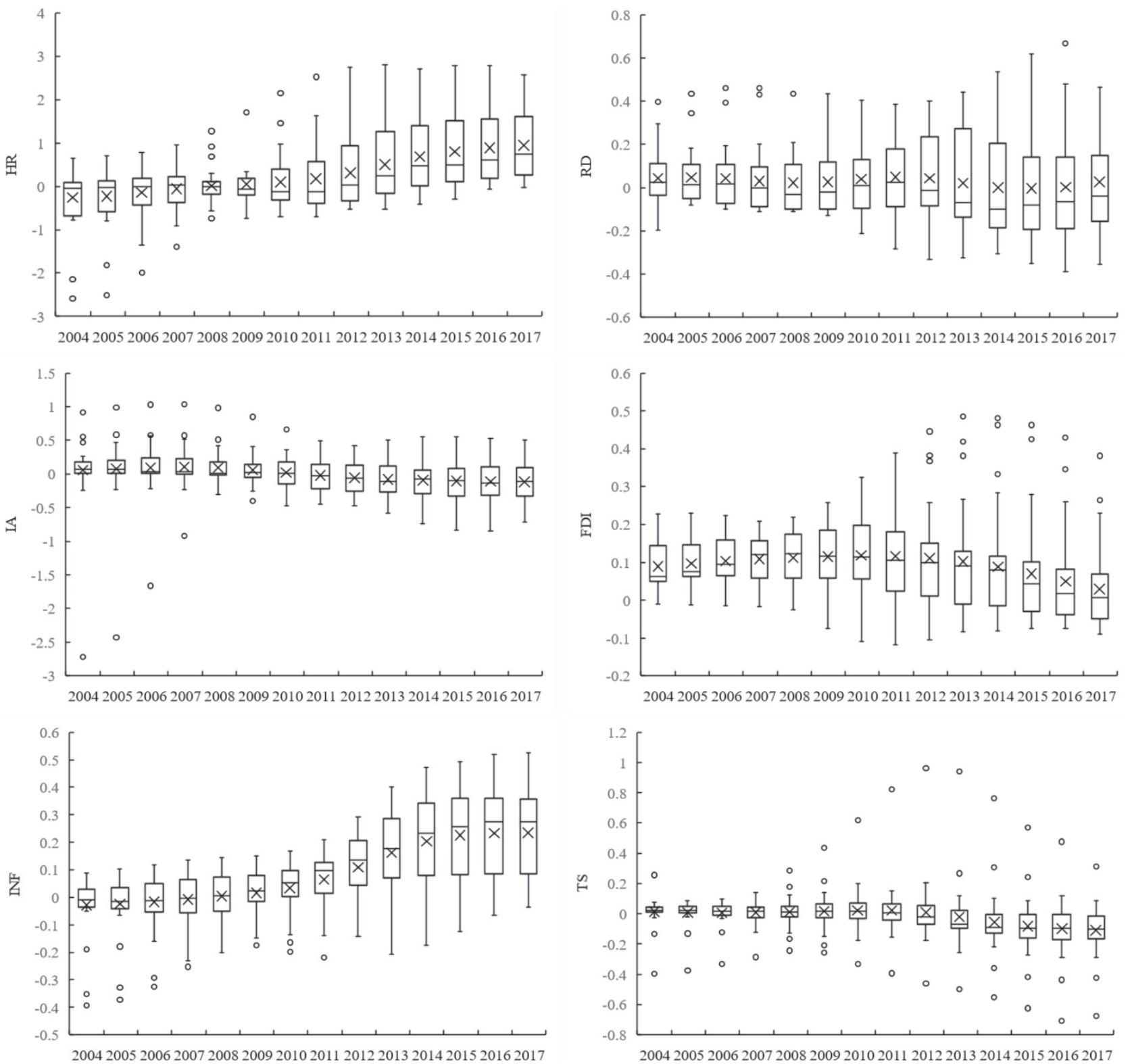

Fig. 3. Time evolution trend of GTWR regression coefficients from 2004 to 2017.

industry, optimize resource allocation, promote the diffusion of green technologies, and then promote the increase of GTFP of the logistics industry. Moreover, from 2004 to 2017, the average values of the regression coefficients of the transportation structure fluctuated greatly. Among them, the mean values of the regression coefficient of transport structure from 2004 to 2012 are greater than 0, while those from 2013 to 2017 are less than 0 . One possible explanation is that the proportion of the highway cargo turnover to the total cargo turnover increased from 0.2048 to 0.4515 during the sample period, that is, the highway has undertaken the long-distance transportation of bulk cargoes that should have been undertaken by railways and waterways. This result leads to an increase in gasoline consumption and ecological destruction, which is not conducive to energy conservation and emission reduction and the improvement of GTFP in the logistics industry, and this is also illustrated in the conclusion drawn by Peng et al. [49].

\section{The Spatial Evolution of the Influences of Factors on GTFP}

In order to more intuitively describe the spatiotemporal heterogeneity of the influences of factors on the logistics industry's GTFP, this paper applies spatial visualization to explore the spatial heterogeneity of the regression coefficients of driving factors, as shown in Fig. 4. As shown in Fig. 4a), the regression coefficients of HR present a decreasing gradient of "east-central-west". One possible explanation is that the eastern coastal regions rely on their strong economic strength and broad development space, which has led to a large number of logistics talents gathering in the coastal regions, giving full play to the "human capital 
a) The average value of regression coefficients of HR (2004-2017)

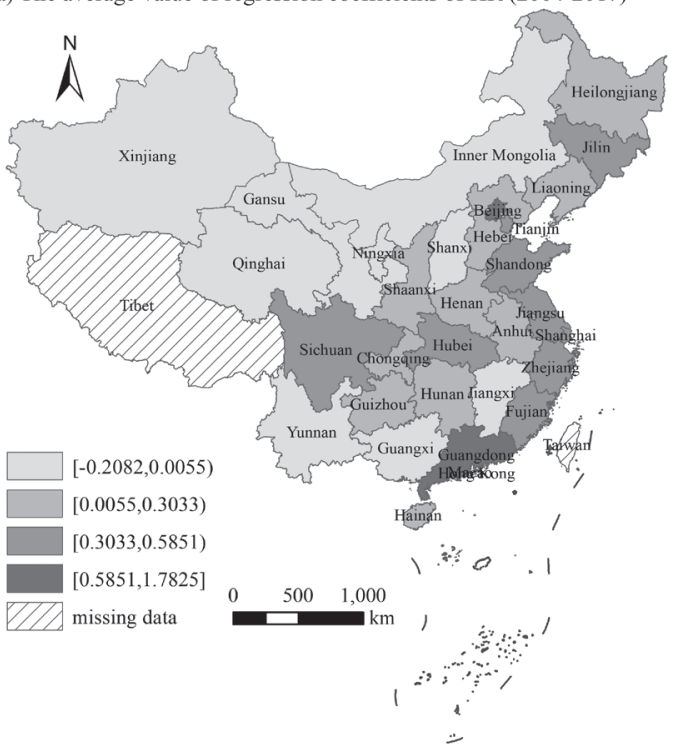

c) The average value of regression coefficients of IA (2004-2017)

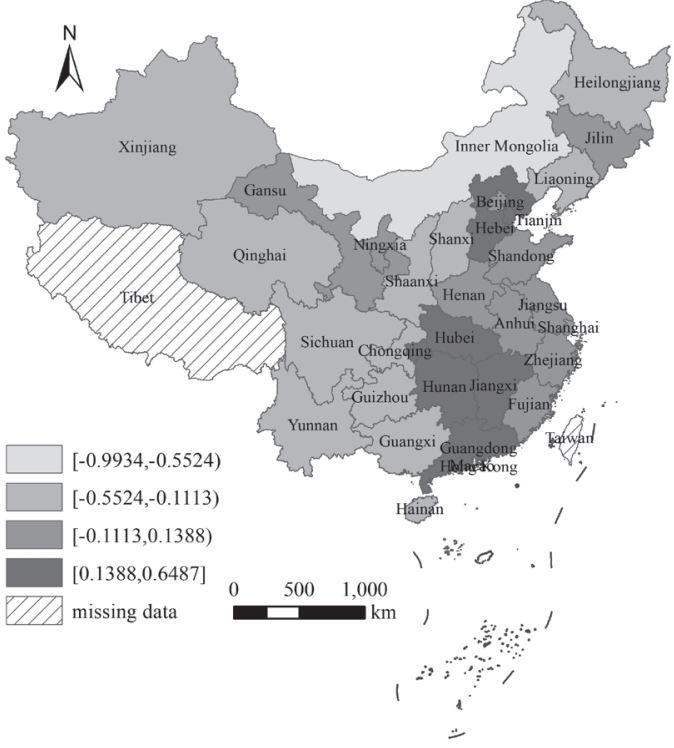

e) The average value of regression coefficients of INF (2004-2017)

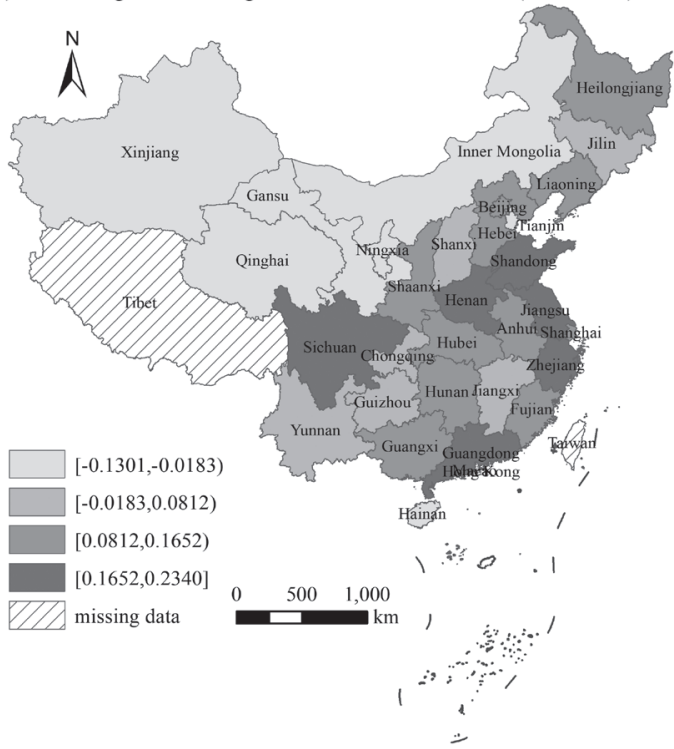

b) The average value of regression coefficients of RD (2004-2017)

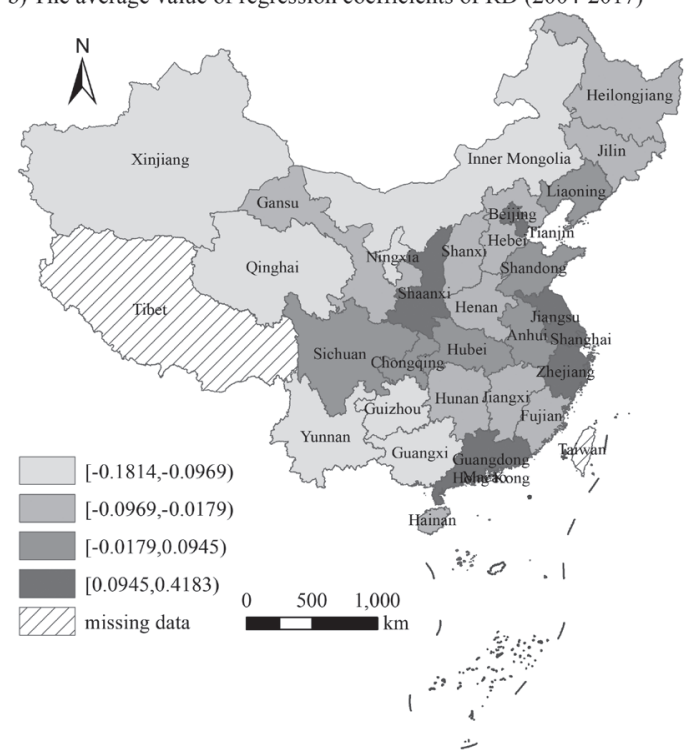

d) The average value of regression coefficients of FDI (2004-2017)

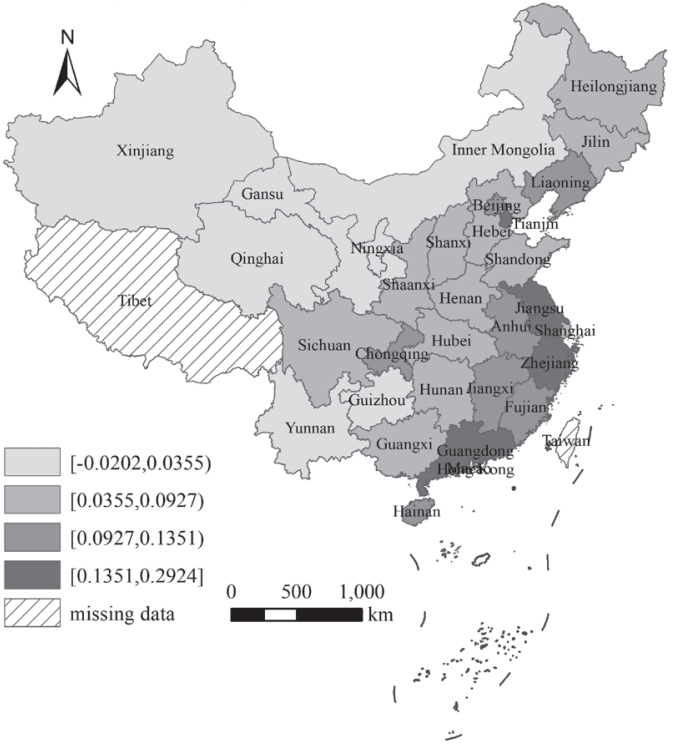

f) The average value of regression coefficients of TS (2004-2017)

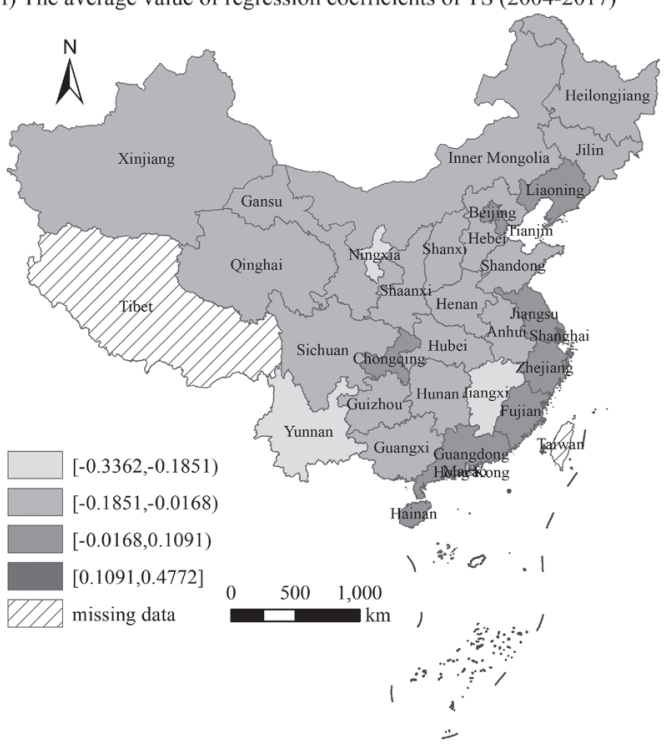

Fig. 4. Spatial distribution of average regression coefficients of driving factors from 2004 to 2017. 
dividend". In contrast, the economic development of the central and western regions is relatively backward and cannot create a good environment for talent development, so it lacks regional appeal. As can be seen in Fig. 4b), the regression coefficients of RD in the eastern coastal regions are relatively high, while those of in the southern and northern regions are relatively low. In some regions, the coefficients are negative, which leads to the phenomenon of "innovation paradox" [50]. The possible explanation is that the intensity of R\&D investment has a threshold effect on GTFP in the logistics industry. When the threshold is crossed, the impact of R\&D investment on the logistics industry's GTFP changes from negative to positive. Moreover, as can be seen in Fig. 4c), The agglomeration of the logistics industry in Beijing, Jiangsu and Zhejiang has exerted a negative inhibitory effect on the logistics industry's GTFP. This indicates that with the continuous expansion of the industrial agglomeration scale, the congestion effect exceeds the scale effect, which is not conducive to the improvement of the logistics industry's GTFP. In contrast, the agglomeration of the logistics industry in Hebei, Hunan, Guangdong and Tianjin has a positive impact on GTFP of the logistics industry, which shows that the agglomeration of the logistics industry in these areas has played a scale effect, which can optimize the allocation of resources and reduce the logistics operation costs of enterprises.

In addition, as shown in Fig. 4d), except Ningxia and Xinjiang, FDI in other provinces in China has promoted the improvement of GTFP in the logistics industry. The level of openness has a greater influence on the logistics industry in the eastern region and a smaller influence on the western region, indicating that there is an uneven phenomenon in attracting FDI among Chinese provinces. That is, compared to the inland areas, the eastern region is the earliest region for reform and opening up in China. Thus, the total amount of FDI and the quality of investment in these regions have continued to improve, which in turn has provided various necessary supports for the green development of the logistics industry. Furthermore, as can be seen in Fig. 4e), the regression coefficient of INF is characterized by "high in central and eastern regions and low in western regions". That is, the informatization infrastructure in the western region is not completed, and the relevant application systems and environment have yet to be optimized. As a result, the contribution of the informatization level to the GTFP of the logistics industry is low. In contrast, in the eastern and central regions, the improvement of INF can meet the development needs of the logistics industry, thus its contribution to the GTFP of the logistics industry is relatively high. Additionally, as shown in Fig. 4f), the regression coefficient of the transportation structure is characterized by "high in coastal areas and low in inland areas". Inland areas of China are far from ports, and water transport is restricted. Meanwhile, inland areas have a sparse railway network with few lines and inconvenient rail transportation. Therefore, the transportation of goods in inland areas mainly depends on roads, which is neither economical nor environmentally friendly.

\section{Conclusions and Policy Implications}

\section{Conclusions}

Based on data from 30 provinces in China from 2004 to 2017, this paper applies the EBM model and GML index to measure the green total factor productivity of the logistics industry, then adopts the geographically and temporally weighted regression to empirically analyze the influences of human resources, $\mathrm{R} \& \mathrm{D}$ investment intensity, the industrial agglomeration, the foreign direct investment, the informatization level and transportation structure on the green total factor productivity of the logistics industry. The conclusions put forward are as follows: (1) The GTFP of China's logistics industry shows significant spatial and temporal differences. Specifically, GTFP of logistics industry indicates a process of alternating changes in ascent and descent, and a "step-like" distribution pattern of high east and low west. (2) GTWR is superior to OLS and GWR. Because compared to OLS and GWR, GTWR has the highest R-square and $F$ value, the lowest AIC value and the sum of squared residuals. (3) The results of GTWR shows that the influences of driving factors on GFTP of the logistics industry have different directions and degrees, showing significant spatiotemporal heterogeneity.

\section{Policy Implications}

Based on the above conclusions, some feasible policy recommendations to further improve the GTFP of the logistics industry in China are proposed.

First, the rapid development of the logistics industry has led to an increase in carbon emissions, so the undesirable output caused by oil consumption cannot be ignored. In particular, the proportion of road transportation in China's logistics industry is very large. The low quality of oils, such as diesel and gasoline, has increased undesirable output. Therefore, the proportion of clean energy such as nuclear power, hydropower, wind power and solar energy should be increased to optimize the energy consumption structure. In addition, the information construction of the logistics industry should be promoted, and the development level of the logistics industry should be improved to promote energy conservation and emission reduction. Moreover, the investment in R\&D funds and the innovation and promotion of energy saving and emission reduction technologies should be increased.

Second, the development of China's logistics industry should not only rely on the input and optimization of resource elements, but also the role of 
technological factors. The calculation result of GTFP shows that although the GTECH of the logistics industry is relatively high, GEFFCH shows a downward trend, so more attention should be paid to the improvement of GEFFCH. Therefore, the focus of logistics development at this stage should be on optimizing the operating environment of the industrial market and improving the level of enterprise management. Through further opening up, transportation infrastructure construction and logistics informatization, the role of resource investment is fully utilized.

Third, the driving factors of GTFP of the logistics industry in each province have different effects on the growth rate, thus the logistics industry's GTFP promotion policy should be formulated according to local conditions. That is, the eastern area should focus on improving the quality and level of utilizing the foreign capital and controlling the scale of agglomeration. In contrast, the central and western regions should attract domestic and foreign investment with technological content. Additionally, the regression results of $\mathrm{HR}$ calculated by GTWR also indicate that attracting and retaining talents are the key factors affecting the green development of the logistics industry in the central and western regions.

Fourth, excessive gaps between provinces in economic development, infrastructure, and human capital have resulted in differences in the directions and degrees of the influences of driving factors on the logistics industry's GTFP. Therefore, governments should establish a cross-regional coordination mechanism, strives to strengthen technical exchanges and cooperation between regions in order to eliminate obstacles to the flow of production factors and information technology exchanges. This can also promote the rapid and effective transfer of advanced energy-saving and emission-reduction technologies to backward areas, and eventually achieve the convergence of the GTFP in the logistics industry across the entire country, the three major regions, and the provinces.

Although this article has conducted in-depth research on the temporal and spatial distribution characteristics and driving mechanism of GTFP in China's logistics industry, and has made some progress, the research still has the following deficiencies: (1) Due to the difficulty in obtaining data, the research sample in this article does not include Tibet, Hong Kong, Macao and Taiwan, and it also lacks cross-country comparative studies with foreign logistics industries; (2) This article only measures the GTFP of the logistics industry, without taking into account its spatial spillover effect.

\section{Acknowledgements}

This study was funded by The National Social Science Fund of China (18BGL018).

\section{Conflict of Interest}

The authors declare no conflict of interest.

\section{References}

1. LIU Z., JIANG Y., BOLAYOG D. Does "replacing business tax with value-added tax" promote the energy efficiency of the logistics industry in China?. Environmental Science and Pollution Research, 26 (32), 33169, 2019.

2. CHARNES A., COOPER W., LEWIN A.Y. Measuring the efficiency of decision making units. Journal of the Operational Research Society, 48 (3), 332, 1978.

3. MARKOVITS-SOMOGYI R., BOKOR Z. Assessing the logistics efficiency of European countries by using the DEA-PC methodology. Transport, 29 (2), 137, 2014.

4. ZHANG Z.J., ZHANG H., LIU J. Technical efficiency measurement and upgrading strategy for the agricultural product logistics industry in China. Agro Food Industry Hi-Tech, 27 (6), 106, 2016.

5. WANG Q., HANG Y., SU B., ZHOU P. Contributions to sector-level carbon intensity change: An integrated decomposition analysis. Energy Economics, 70, 12, 2018a.

6. CHEN S., GOLLEY J. 'Green' productivity growth in China's industrial economy. Energy Economics, 44, 89, 2014.

7. SONG M., LI H. Total factor productivity and the factors of green industry in Shanxi Province, China. Growth and Change, 2019, doi:10.1111/grow.12339.

8. LONG X., ZHAO X., CHENG F. The comparison analysis of total factor productivity and eco-efficiency in China's cement manufactures. Energy Policy, 81, 61, 2015.

9. CHAMBERS R.G., CHUNG Y., FARE R. Benefit and distance functions. Journal of Economic Theory, 70 (2), 407, 1996.

10. CHUNG Y., FARE R., GROSSKOPF S. Productivity and undesirable outputs: A directional distance function approach. Journal of Environmental Management, 51 (3), 229, 1997.

11. LI K., LIN B. Economic growth model, structural transformation, and green productivity in China. Applied Energy, 187 (2), 489, 2017.

12. SHEN N., LIAO H., DENG R., WANG Q. Different types of environmental regulations and the heterogeneous influence on the environmental total factor productivity: Empirical analysis of China's industry. Journal of Cleaner Production, 211, 171, 2018.

13. SIMPSON H. How do Firms' outward fdi strategies relate to their activity at home? empirical evidence for the UK. World Economy, 35 (3), 243, 2012.

14. HERRIGEL G. Globalization and the German industrial production model. Journal for Labour Market Research, 48(2), 133, 2015.

15. HU J.F., WANG Z., LIAN Y.H., HUANG Q.H. Environmental regulation, foreign direct investment and green technological progress-evidence from Chinese manufacturing industries. International Journal of Environmental Research and Public Health, 15, 221, 2018.

16. ZHOU Y., JIANG J., YE B., HOU B. Green spillovers of outward foreign direct investment on home countries: Evidence from China's province-level data. Journal of Cleaner Production, 215, 829, 2019.

17. CUI H., WANG H., ZHAO Q. Which factors stimulate industrial green total factor productivity growth rate in 
China? An industrial aspect. Greenhouse Gases: Science and Technology, 9 (3), 505, 2019.

18. RAHMAN S., SALIM R. Six decades of total factor productivity change and sources of growth in Bangladesh agriculture (1948-2008). Journal of Agricultural Economics, 64 (2), 275, 2013.

19. SONG M., DU J., TAN K.H. Impact of fiscal decentralization on green total factor productivity. International Journal of Production Economics, 205, 359, 2018.

20. LIU Z., XIN L. Has China's Belt and Road Initiative promoted its green total factor productivity? - Evidence from primary provinces along the route. Energy Policy, 129, 360, 2019.

21. ZHOU Y., XU Y., LIU C., FANG Z., FU X., HE M. The threshold effect of China's financial development on green total factor productivity. Sustainability, 11, 3776, 2019.

22. YANG J., TANG L., MI Z., LIU S., LI L., ZHENG J. Carbon emissions performance in logistics at the city level. Journal of Cleaner Production, 231, 1258, 2019.

23. YANG J.K., MAO B.W., HU H. Total factor energy efficiency of the logistics industry in the Yangtze river economic belt - based on SBM and GML index models including carbon emissions. Journal of Beijing Institute of Technology, 18 (6), 54, 2016 [In Chinese].

24. TONE K. A slacks-based measure of efficiency in data envelopment analysis. European Journal of Operational Research, 130 (3), 498, 2001.

25. TONE K., TSUTSUI M. An epsilon-based measure of efficiency in DEA - A third pole of technical efficiency. European Journal of Operational Research, 207 (3), 1554, 2010.

26. WU P., WANG Y., CHIU Y., LI Y., LIN T.Y. Production efficiency and geographical location of Chinese coal enterprises - undesirable EBM DEA. Resources Policy, 64, $1,2019$.

27. WANG Q., HANG Y., HU J.L., CHIU C.R. An alternative metafrontier framework for measuring the heterogeneity of technology. Naval Research Logistics, 65 (5), 427, 2018b.

28. OH D.H. A global Malmquist-Luenberger productivity index. Journal of Productivity Analysis, 34 (3), 183, 2010.

29. STEWART F.A., CHARLTON M., BRUNSDON C. The geography of parameter space: An investigation of spatial non-stationarity. International Journal of Geographical Information Systems, 10 (5), 605, 1996.

30. HUANG B., WU B., BARRY M. Geographically and temporally weighted regression for modeling spatiotemporal variation in house prices. International Journal of Geographical Information Science, 24 (3), 383, 2010.

31. FOTHERINGHAM A.S., CRESPO R., YAO J. Geographical and temporal weighted regression (GTWR). Geographical Analysis, 47 (4), 431, 2015.

32. CHU H.J., HUANG B., LIN C.Y. Modeling the spatiotemporal heterogeneity in the PM10-PM2.5 relationship. Atmospheric Environment, 102, 176, 2015.

33. MA X., ZHANG J., DING C. A geographically and temporally weighted regression model to explore the spatiotemporal influence of built environment on transit ridership. Computers Environment and Urban Systems, 70, 113, 2018.
34. TANG J., WANG Q., CHANG Y.T. China's regional industrial two-stage system - Efficiencies and their influencing factors. Journal of Cleaner Production, 249, 119420, 2020.

35. WU Y. China's capital stock series by region and sector. Frontiers of Economics in China, 11 (1), 156, 2016.

36. LI H., HE F., DENG G. How does environmental regulation promote technological innovation and green development? New evidence from China. Polish Journal of Environmental Studies, 29 (1), 689, 2020.

37. WU Y. Is China's economic growth sustainable? A productivity analysis. China Economic Review, 11 (3), 278, 2000.

38. VAIZEY J., SCHULTZ T.W. Investment in human capital. The Economic Journal, 82 (326), 787, 1972.

39. TAO F., ZHANG H., HU Y. Growth of green total factor productivity and its determinants of cities in China: A spatial econometric approach. Emerging Markets Finance and Trade, 53 (2), 1, 2017.

40. BENGOA M., ROMÁN V.M.S., PÉREZ P. Do R\&D activities matter for productivity? A regional spatial approach assessing the role of human and social capital. Economic Modelling, 160, 448, 2017.

41. VOUTSINAS I., TSAMADIAS C. Does research and development capital affect total factor productivity? Evidence from Greece. Economics of Innovation and New Technology, 23 (7), 631, 2014.

42. FUTAGAMI K., OHKUSA Y. The quality ladder and product variety: Larger economies may not grow faster. The Japanese Economic Review, 54 (3), 336, 2003.

43. LIST J.A., CO C.Y. The effects of environmental regulations on foreign direct investment. Journal of Environmental Economics \& Management, 40 (1), 1, 2000.

44. SALAIMEH S.A.A. A new model for information logistics system architecture. Journal of Theoretical and Applied Information Technology, 28 (1), 39, 2011.

45. CHOY K.L., GUNASEKARAN A., LAM H.Y. Impact of information technology on the performance of logistics industry: The case of Hong Kong and Pearl Delta region. Journal of the Operational Research Society, 65 (6), 904, 2014.

46. TIMILSINA G.R., SHRESTHA A. Transport sector $\mathrm{CO}_{2}$ emissions growth in Asia: Underlying factors and policy options. Energy Policy, 37 (11), 4523, 2009.

47. MOHAMAD R.S., VERRASTRO V., AL BITAR L., ROMA R., MORETTI M., AL CHAMI Z. Effect of different agricultural practices on carbon emission and carbon stock in organic and conventional olive systems. Soil Research, 54 (2), 173, 2016.

48. CHEN Y., LI M., SU K., LI X. Spatial-temporal characteristics of the driving factors of agricultural carbon emissions: Empirical evidence from Fujian, China. Energies, 12 (16), 3102, 2019

49. PENG Z.M., WU Q.Q., WANG D.F., LI M. Temporalspatial pattern and influencing factors of china's provincelevel transport sector carbon emissions efficiency. Polish Journal of Environmental Studies, 29 (1), 233, 2020.

50. PESSOA A. R\&D and economic growth: How strong is the link?. Economics Letters, 107 (2), 152, 2010 